\title{
Measuring the Quality of Records to Improve Organizational Documentary Testimony
}

\author{
Basma Makhlouf Shabou, Ph.D \\ Professor, Department of Information Studies University of Applied Sciences Western Switzerland \\ basma.makhlouf-shabou@hesge.ch
}

\begin{abstract}
This paper presents the important elements of doctoral research into archival science at the Université de Montréal - Ecole de bibliothéconomie et des sciences de information, about the definition and the measurement of the dimensions of quality applied to historical archives. It focuses mainly on three questions: first, what are intrinsic and extrinsic archival qualities; second, what conceptual framework can integrate and structure various dimensions of intrinsic and extrinsic qualities of archival documents; third, which indicators and variables should be tested to verify the measurability of these qualities. After developing a conceptual framework distinguishing four dimensions of quality of archives, a quantitative and descriptive study was conducted to confirm the measurability of fourteen variables of two of these four dimensions that were measured: the credible evidence as an intrinsic dimension example and the exploitability as an extrinsic dimension example.
\end{abstract}

Index Terms - Quality, archives, archival appraisal, measurement, indicators measurement, application guide, archival metrics, institutional memory.

\section{INTRODUCTION}

In archival science, the interest in studying the concept of quality is not the most discussed topic. The literature review helped to identify characteristics that were recognized, often implicitly, as desired qualities in the archives, such the trustworthiness of the documents (), authenticity, reliability, integrity. Except for ISO 15489 [1a], [1b], which addressed, intentionally, the characteristics of archives in a quality perspective, the qualities identified in the writings were in most cases addressed indirectly through the study of the probative ability of documents generally related to the nature of archives [2] - [6] and in particular to studies about the characteristics of electronic records and their preservation [6] - [9a].
Some decades ago, interest in studying the archival appraisal function was diversified to deepen theoretical principles and their implementation process - techniques, instruments and criteria. However, all these contributions have not yet studied the nature of appraisal results: historical archives. These archives are the documents which are regarded as the best documentary materials to reflect the image, context, structure, functions and activities of their agency producer.

\section{PROBLEM}

As defined by the Society of American Archivists, the archival science "is a systematic body of theory that supports the practice of appraising, acquiring, authenticating, preserving, and providing access to recorded materials" [9b]. The topic of archiving and choosing the document worthy of inclusion in institutional memory is a great challenge for archivists. This preoccupation can be explained by many factors. First, from the perspective of documentary heritage, the lack of studies on the definition and measurement of the quality of historical archives prevents verification as to whether archival materials are significant. Second, at the administrative level, the current practice of appraisal does not yet invest in a meticulous examination of the nature of documents that we should conserve permanently. Third, in economic terms, the lack of methods and tools to measure the quality of archives, affects the archivist's judgments whether these records are judged to be worth the material, technical, financial and human investment that their preservation requires. Finally, from a professional standpoint, the absence of methods and instruments to assess the quality of archives prevents professionals from supporting their decisions on archival appraisal.

\section{PURPOSE}

This research aims to define and measure the qualities of archives derived from an archival appraisal process. Specifically, this research aims to: 
1) identify the concepts of quality appropriate to the historical archives,

2) propose a framework to define and organize the dimensions of intrinsic and extrinsic qualities of historical archives;

3) test the validity of this conceptual framework by measuring the variables arising from some aspects of intrinsic and extrinsic qualities of historical archives.

\section{LITERATURE REVIEW}

Three sources were considered in the literature. The first is the literature on the genesis of the concept and measurement of quality. The second source is the literature on the concept of quality in information sciences. The third source is the literature on the archival appraisal function and the writings that bear on the concept of quality archival in mainly in contemporary European, North American and Australian. Overall, the literature on these topics covers the last thirty years.

The writings of quality experts focused on the emergence, evolution, definition and measurement of the quality concept. Five elements are considered in defining and measuring quality, namely : 1) its definition as the intrinsic and extrinsic characteristics that are related to objective and subjective dimensions [10] - [15], 2) its dual purpose of, firstly, meeting the needs expressed and explicit and, secondly, ensuring the functions to which a product or service expected to respond [10] - [23], 3) its multidisciplinary, multidimensional, contextual, relative and variable nature [11], [12], [14], [17], 4) the fact that its measure, in addition to its essential character and systematic, is realized by a process, with indicators associated with intrinsic or extrinsic dimensions, and leads to interpretable concrete results [16], 5) and the necessity of a metric to ensure its control and its improvement [16], [24].

The explored literature in information sciences on the concept of quality applied to information or on an aspect related to its nature and its creation or use context (data, information systems, documents, library, archives, etc.) points out two main considerations: first, the definition of quality in information sciences should include both the intrinsic and extrinsic dimensions, which may be objective and/or subjective [15], [26]; second, this definition should be based on a continuous improvement [25].

Quality according to information sciences is widely linked to two important constituents, first the satisfaction of the user to whom this information is ultimately served; second, the ability of a product or service to perform its requirements. For some authors, quality is a component in theoretical models, such as the model of goodness libraries [27] or the model of information systems [28]. In the same vein, we may have other examples as the model of value added information systems [29] and also the model that explores the concept of relevance [30] - [33].

Similarly, the idea of the need to measure the quality of information was extensively treated and widely recognized. The reviewed literature confirmed the multidimensional nature of quality and its measurement. The operation of quality measurement is based on dimensions, indicators and its derived variables [34], [35].

\section{CONCEPTUAL FRAMEWORK}

As mentioned above, the second purpose of this study is to propose a conceptual framework for defining the dimensions of intrinsic and extrinsic qualities of archives. Several studies in information sciences have been interested in the study of quality. To assess the quality of data, for example, several authors have defined a conceptual framework that subdivides a complex concept in various dimensions covering an aspect about it. Defining the dimensions and identifying the indicators are the basic steps necessary to deepen the definition of a concept as complex as quality.

To build the conceptual framework, we distinguished four levels: the dimensions, the general indicators (level 1), the general indicators (level 2) and finally specific indicators. As shown in Figure 1, levels are presented in a hierarchical structure of concepts from the general to the more specific.

\section{Dimension}

Concept represents a general level of quality. It may be an intrinsic dimension related to the nature of archives or an extrinsic dimension related to the context of archives [10], [16]. It can also be objective as it can be subjective [11], [15].

\section{Sub-dimension}

Concept which is derived from a quality dimension whose role is to allow the precision of a conceptual dimension and to facilitate its measurement.

\section{General indicator}

A conceptual level that clarifies and deepens the concepts presented in the previous level, given the complexity of the dimension.

\section{Specific indicator}

Still conceptual but more accurate in defining the hierarchy of quality dimensions of historical archives (QADs). It provides a framework for identifying variables and a basis for developing observable measurement. This level is the relationship between the conceptual levels on the one hand, and the operational and concrete levels on the other. 


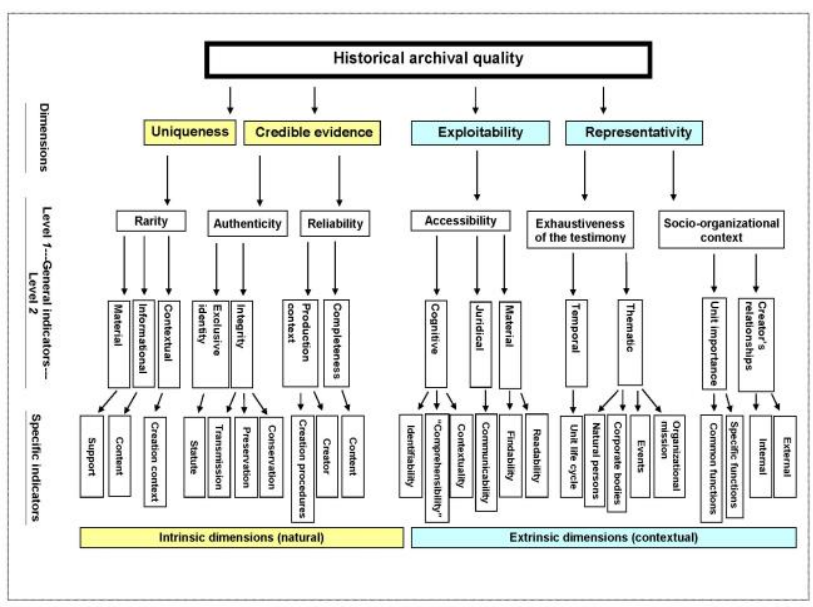

FIGURE 1. CONCEPTUAL FRAMEWORK: DEFINITION OF HISTORICAL ARCHIVAL QUALITY

Considering its multidimensional nature, the qualities of archives, according to our research, are organized into four major dimensions, two dimensions related to the intrinsic nature of archives (content, material, format, etc.): the uniqueness and the credible evidence and two dimensions that are extrinsic rather related to the context of production and use of archives, which are the exploitability and the representativity.

\section{Uniqueness}

Intrinsic dimension that is defined by one or more aspects related to their rarity. The concept of uniqueness discussed here is based on the concept of Scarcity proposed by Boles and Young [36] and the concept of uniqueness suggested by Menne-Haritz [37].

\section{Credible evidence}

Ability of a document to gain the trust of the user as the preferred source to support the facts, which is based on authenticity and reliability [38].

\section{Exploitability}

Any issue that could facilitate and promote the use of archives. It is based on three kinds of accessibility: juridical, cognitive and material [1a], [1b]. This means respectively, 1) the legal and regulatory permission that allows for consultation and reproduction of records, 2) the ease of access content archives and their context of creation, and 3) the ease of access document's a medium which is based on its physical location and also on its readability.

\section{Representativity}

Ability of archives to allow significant information reflecting the organizational context of their creation. This quality depends on two essential elements: comprehensiveness and representativeness of socioorganizational evidence.

The choice of all the qualities that constitute the conceptual framework was made mainly on the basis of four criteria related to the purpose of this research: defining and measuring qualities of the historical archives and identifying its variables that enables their operationalization. Thus, we are interested in the qualities that 1) allow a precise definition, 2) provide relevant concepts and indicators to the measurement of quality dimensions, 3) are appropriate to the nature and context of archives 4) are recognized by several authors in various literature sources mentioned above.

\section{MeTHODOLOGY}

Our research seeks to define and measure the quality of archives. For the implementation of the research, we use a quantitative descriptive methodology, strongly suggested when we have to deal with unexplored topics [39] as the definition and measurement of archival quality.

Considering the third research aim that consists to test the validity of this conceptual framework by measuring the variables arising from intrinsic and extrinsic qualities of archives, two phases constitute the research strategy. A conceptual phase, in which four quality dimensions of historical archives have been identified and defined. Then an empirical phase aimed to verify the measurability of variables derived from only two quality dimensions in the context of historical archives produced by governmental structures. For reasons of feasibility research, credible evidence and exploitability are the selected dimensions for the empirical phase of the study.

Specifically, in the first instance a preliminary experiment (prestest) was conducted to verify the validity of 13 indicators that derive from two quality's dimensions. Twenty-four variables were identified for this preliminary phase. The completion of the experiment and analysis of its results led to the revision and the adjustment of variables and their measurement. In sum, this review was to reduce the 24 variables to 14 variables selected for this research. Considering validity criteria and given the advancement of research in the field of quality records and the exploratory nature of research in measuring qualities of archives in particular, we chose to limit the scope of our study to only two quality dimensions and their 13 specific indicators including their 14 emerging variables. Adjusting aspects of the test is an approach quite legitimate, even expected in the model of study design, especially as this is pioneering work in adapting the concept of quality to the archives.

Three measurement grids were developed in order to implement the measurement on three documentary levels: fund, file and item. The structure of every grid, including its contents is fashioned on the basis of the conceptual 
definition of QADs: dimensions, their broad indicators level 1 and 2 and their specific indicators as specified in the conceptual framework. A criterion sampling has been conducted. The measurement grids have been applied on 36 files chosen from six governmental archival funds. The measurement of every variable was implemented by responding to a question. The result of measurement consisted of assigning a level of quality among five. The highest (level 5) corresponds to the situation of the most perfect quality from the perspective of the question purpose. Level 1 reflects the lowest quality level. The measures were undertaken by an ordinal scale, whose main objective is to evaluate the variables by releasing an order of magnitude, and the numbers obtained indicate the ranks and not quantity. We get a number indicating a level of quality in terms of the purpose of each question. Thus, the quality level for each question is quantified.

In addition, an implementation guide to the measurement grid was established, first, to facilitate the implementation of this measuring instrument; and second, to enhance the reproducibility of the measurement method of other researchers. The purpose of this guide is to clarify the attribution of every score which indicates one level of quality among five. It defines and justifies each quality level, specifying the requirements for each of these five quality levels. This instrument also contains examples to explain certain technical aspects of the proposed measures.

\section{RESULTS}

To illustrate the type of results obtained from completion of this empirical step of research, an example follows:

For measuring the transmission modes of documents: one of four variables related to documentary fund ${ }^{1}$ is examined by the question: 'By which mode was the fund sent to the Bibliothèque Archives nationales du Québec (BAnQ). As shown in Table 1, in response to this question and after exploring information available in the research instruments about each one of six government archival funds, we attribute a score (from 1 to 5) reflecting the quality level from the point of view of this variable.

Table 1. MEASUREMENT OF ARCHIVAL QUALITY FROM THE POINT OF VIEW OF ITS TRANSMISSION: EXAMPLE

\section{Quality Levels}

\section{Variable 3. Transmission Mode}

\footnotetext{
${ }^{1}$ It represents a general and largest documentary level that includes series, files and items which are produced by the same person or institution. They are created and accumulated as the result of an organic process reflecting the functions of the creator. (Society of American Archivists, 2005)
}

5. Straight from the creator with an acquisition agreement

4. Directly without the creator's acquisition agreement

3. By a known intermediate with an acquisition agreement

2. By two identified intermediates or more without acquisition Agreement

1. Mode of transmission is unknown

As shown in Table 2, the examination of six funds distinguishes different qualities according specific modes and contexts that characterize the transmission of each fund.

TABLE 2. SYNTHESIS OF THE RESULTS OF MEASUREMENTS OF VARIABLES RELATED TO THE DOCUMENTARY FUND

\begin{tabular}{|l|c|c|c|c|c|c|}
\hline \multicolumn{1}{|c|}{ Fund } & $\mathrm{F}$ & $\mathrm{F}$ & $\mathrm{F}$ & $\mathrm{F}$ & $\mathrm{F}$ & $\mathrm{F}$ \\
& 1 & 2 & 3 & 4 & 5 & 6 \\
\hline Variables & & & & & & \\
\hline $\begin{array}{l}\text { V.3 Transmission mode } \\
\text { level }\end{array}$ & $\mathbf{4}$ & $\mathbf{4}$ & $\mathbf{4}$ & $\mathbf{5}$ & $\mathbf{2}$ & $\mathbf{2}$ \\
\hline V.6 Conservation conditions & 2 & 5 & 5 & 5 & 5 & 5 \\
\hline V.12 Description level & 5 & 4 & 5 & 5 & 5 & 5 \\
\hline
\end{tabular}

This is a part of the results concerning four variables related to fund (Table 2). The 10 other variables were tested on 36 files and items in different supports generated into many specific and general activities of six governmental organizations, following the same principle.

The data collection was based on the application of a historical archives measurement grid. The completion of data collection which took place at the Bibliothèque Archives nationales du Québec (BAnQ) and their processing has enabled the operationalization of 10 specific indicators out of 13 belonging to two dimensions of quality: "Credible evidence" and "Exploitability" of archives. In short, this means that three specific indicators out of 13 were defined but their measurement was not possible because of a weakness detected during pretests. These three specific indicators are, on the one hand, the "Creator" in the dimension of the "Credible evidence" and on the other hand, "Comprehensibility" and "Findability" in the dimension of "Exploitability".

Analysis of data was descriptive, appropriate in such exploratory studies. According to this descriptive analysis, we discuss the features that emerge from the measurements and draw comparisons and associations between variables.

The fund, file and item measurements were conducted to identify weaknesses and improve several variables related to the creator, the conservation office or the state 
and the nature of the support. Targeting the improvement of a product or service is, as demonstrated in the literature review, the ultimate goal of a study on the definition of the dimensions of quality and the measurement of their different indicators.

\section{CONCLUSION}

Our research which is defining and measuring the quality of archives promises three significant benefits. In theory, it develops a conceptual framework that offers the definition of the dimensions of the concept of historical archival quality derived from the appraisal process. At the methodological level, it offers a method for measuring the quality of historical archives already tested in the context of a government agency.

At the professional level, firstly, it allows the assessment of the relevance of archival material that has been chosen for the appraisal; furthermore, it provides professionals a measurement grid for measuring historical archival qualities already tested and also the guide that facilitates its application.

This study is the first reflection that was done in the domain of archival quality assessment. At this exploratory step, we could not pretend to offer the way that measures exhaustively the quality of an institutional archives. To do this, the research should be reproduced in different documentary context to be confirmed and reinforced. The completion of the measurement related to rarity and representatively of archives, two quality's dimensions that were not measured in this research, is necessary for the validity of research's conceptual framework and its result's relevance.

\section{REFERENCES}

[1a] International Organization for Standardization, ISO 154891:2001 Information and documentation-Records management-Part1: General. Geneva: ISO, 2001.

[1b] International Organization for Standardization, ISO/TR 15489-2:2001 Information and documentation-Records management_Part2: Guidelines. Geneva: ISO, 2001.

[2] H. Jenkinson, A manual of archive administration. $3^{\text {rd }}$ ed. London: Percy Lund Humphries and Co., 1965.

[3] T. R. Schellenberg, Modern Archives: Principles and Techniques. Chicago, IL: The University of Chicago Press, 1956.

[4] T. R. Schellenberg, The Management of Archives. New York, NY: Columbia University Press, 1965.

[5] S. McKemmish, "Recordkeeping, Accountability and Continuity: the Australian Reality," in Archival Documents: Providing Accountability Through Recordkeeping. Melbourne: Ancora Press, 1993, pp. 9-26.
[6] W. Duff, "Ensuring the Preservation of Reliable Evidence: A Research Project Funded by the NHPRC," Archivaria, no. 42, pp. 28-45, Fall 1996.

[7] L. Duranti and H. MacNeil, "The Protection of Integrity of Electronic Records: An Overview of the UBC-MAS ResearchProject," Archivaria, no. 42, pp. 46-67, Fall 1996.

[8] C. M. Dollar, Authentic Electronic Records: Strategies for Long-Term Access. Chicago, IL: Cohasset Associates, Inc., 2000 .

[9a] L. Duranti, "Reflections on InterPARES. The InterPARES 2 Project (2002-2007): An Overview," Archivaria, no. 64, pp. 113-121, Fall 2007.

[9b] Society of American Archivists. A Glossary of Archival and Records Terminology. 2005. [Online]. Available: http://www.archivists.org/glossary/term details.asp?DefinitionK $\underline{\text { ey }=1814}$

[10] G. S. Radford, The Control of Quality in Manufacturing. New York, NY: The Ronald Press Company, 1922.

[11] D. A. Garvin, "Competing on the Eight Dimensions of Quality," Harvard Business Review, vol. 65, no. 6, pp. 101-109, November-December 1987.

[12] J. Kélada, Comprendre et réaliser la qualité totale. $2^{\text {nd }}$ ed. Dollard-des-Ormeaux, QC: Quafec, 1991.

[13] M. Périgord and J.-P. Fournier, Dictionnaire de la qualité : français-anglais. La Plaine Saint-Denis: AFNOR, 1993.

[14] M. E. Milakovich, Improving Service Quality: Achieving High Performance in the Public and Private Sectors. Delray Beach, FL: St. Lucie Press, 1995.

[15] B. Stvilia, Measuring Information Quality. Unpublished Ph.D. Urbana-Champaign, IL: University of Illinois at UrbanaChampaign, 2006.

[16] J. M. Juran, Quality - Control Handbook. Toronto, ON: Graw-Hill., 1951.

[17] A. V. Feigenbaum, Total Quality Control. $3^{\text {rd }}$ ed. New York, NY: McGraw-Hill, 1983.

[18a] P. B. Crosby, La qualité sans larmes: l'art de gérer sans problèmes. Paris : Economica, 1986.

[18b] P. B. Crosby, La qualité, c'est gratuit: l'art et la manière d'obtenir la qualité. Paris : Economica, 1986.

[19] Gouvernement du Québec. Ministère de l'industrie et du commerce: Direction des biens d'équipement, Gérer la qualité: pourquoi et comment. Québec: Ministère de l'industrie et du commerce, 1986. 
[20] V. Defourney, D. Noyé and Ministère de l'Industrie de la Poste et des Télécommunications, Du bon usage des mots de la qualité. Paris: INSEP, 1996.

[21] B. Froman and C. Gourdon, Dictionnaire de la qualité: plus de 800 définitions, équivalents anglais, informations normatives commentées. La Plaine Saint-Denis: AFNOR, 2003.

[22] A. Rey and P. Robert, Le Grand Robert de la langue française. Paris: Dictionnaire le Robert, 2005.

[23] Office québécois de la langue française, Le Grand dictionnaire terminologique (GDT), 2002-2010. [Online]. Available: http://www.oqlf.gouv.qc.ca/ressources/gdt.html

[24] J. M. Juran, La qualité dans les services. Paris: Association française de normalisation, 1987.

[25] É. Sutter, Documentation, information, connaissances: la gestion de la qualité. $2^{\text {nd }}$ ed. Paris: ADBS, 2002.

[26] B. K. Kahn, D. M. Strong and R. Y. Wang, "Information Quality Benchmarks: Product and Service Performance," Communications of the ACM, vol. 45, no. 4, pp. 184-192, 2002.

[27] R. M. Orr, "Measuring the Goodness of Library Services: a General Framework for Considering Quantitative Measures," Journal of Documentation, vol. 29, no. 3, pp. 315-332, 1973.

[28] M. Buckland, Information and Information Systems. New York, NY: Greenwood Press, 1991.

[29] R. S. Taylor, Value-added processes in information systems. Norwood, NJ: Ablex publishing corporation, 1986.

[30] T. Saracevic, "Relevance: A Review of the Literature and a Framework for Thinking on the Notion in Information Science," Journal of the American Society for Information Science, November-December, pp. 321-343, 1975.

[31] T. Saracevic, "Information Science," Journal of the American Society for Information Science, vol. 50, no.12, pp. 1051-1063, 1999.

[32] T. Saracevic, "Relevance: A Review of the Literature and a Framework for Thinking on the Notion in Information Science. Part II," Advances in Librarianship, vol. 30, pp. 3-71, 2006.

[33] I. Ruthven, M. Baillie and D. Elsweiler, "The Relative Effects of knowledge, Interest and Confidence in Assessing Relevance," Journal of Documentation, vol. 63, no. 4, pp. 482504, 2007.

[34] R. W. Wang and D. M. Strong, "Beyond Accuracy: What Data Quality Means to Data Consumers," Journal of Management Information Systems, vol. 12, no. 4, pp. 5-33, 1996.

[35] C. Cappiello, C. Francalanci and B. Pernici, "Data quality assessment from the user's perspective.," Information Quality in Informational Systems Proceedings of the 2004 international workshop on Information Quality in Information Systems, pp. 68-73, 2004. [Online].

Available: http://portal.acm.org/citation.cfm?id=1012465

[36] F. Boles and J. M. Young, Archival Appraisal. New York, NY: Neal-Schuman Publishers, 1991.

[37] A. Menne-Haritz, "Appraisal or Selection: Can Content Oriented Appraisal be Harmonized with the Principle of Provenance?," The Principle of Provenance: Report from the First Stockholm Conference on Archival Theory and the Principle of Provenance, 2-3 September 1993. Stockholm: Swedish National Archives, pp. 103-131, 1994.

[38] InterPARES 2 Terminology Database. InterPARES 2 Project Dictionary, 2010. [Online].

Available:

http://www.interpares.org/ip2/ip2_terminology_db.cfm

[39] M.F. Fortin, Fondements et étapes du processus de recherche. Montréal, QC: Chenelière education, 2006.

\section{ABOUT THE AUTHOR}

Dr. Basma Makhlouf Shabou, is a professor of archival science at University of Applied Sciences Western Switzerland, following a doctoral research that she conducted at the University of Montreal's School of Library and Information Sciences (EBSI, 2010). She holds a Master's degree in Social Studies and a Postgraduate degree in Records Management. Her research focuses on defining and measuring the quality of documents; usability issues related to accessibility of documents; relevance and representativeness of archives; archival appraisal and the value of documents. 